
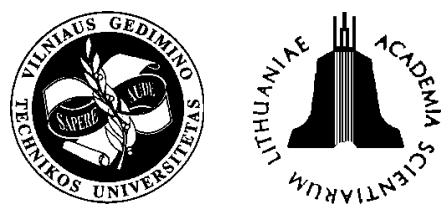

ISSN 1648-4142 TRANSPORT

http:/www.vtu.lt/english/editions

TRANSPORT - 2004, Vol XIX, No 3, 141-147

\title{
THE INFLUENCE OF THE UNLOADING MODE OF ASPHALT CONCRETE MIXING PLANT HOT BIN ON THE HOMOGENEITY OF SCREENED FRACTIONS
}

\author{
Henrikas SiviIevičius \\ Dept of Transport Technological Equipment, Vilnius Gediminas Technical University, Plytinès g. 27, LT-10105 \\ Vilnius-16, Lithuania. E-mail: henrikas@ti.vtu.lt tel. (+370 5) 2744783, fax: (+370 5) 2745060
}

Received 200312 20; accepted 20040401

\begin{abstract}
The analysis of hot asphalt concrete mixture production in asphalt concrete mixing plants of intermittent operation according to the traditional technology scheme is presented. The segregation degree of hot mineral materials fractions of 0-5 mm and 5-15 mm sieved in hot bins and the influence of their screening mode on the homogeneity of the flow running to the measuring hopper were identified during the experimental tests carried out in two asphalt concrete mixing plants. To evaluate the degree of segregation and kinetics according to three different methodologies 214 separate samples of hot fractions grouped into three series A, B, C were taken. Statistical characteristics of each series samples grading and coarseness modulus (fraction of 0-5 mm) as well as arbitrary coarseness modulus (fraction of 5-15 $\mathrm{mm}$ ) were identified. The data analysis proved that the degree of segregation of hot materials sieved in the bin sections is high and the homogeneity of their flows decreases when the range and frequency of quantity fluctuation increases.
\end{abstract}

Keywords: asphalt concrete mixture, production technology, hot materials, working mode, homogeneity, segregation.

\section{Introduction}

Asphalt concrete mixtures (ACM) to be laid and compacted setting up the road pavement layers shall ensure rigid concrete of optimal structure and characteristics which would resist the impact of transport and climate factors for a long time. The components of the mixture produced industrially in an asphalt concrete mixing plant (ACMP) shall not deviate from their project values specified in the norms $[1,2]$ but shall be homogeneous as well.

The accuracy and stability of ACM composition depend on the paramaters of its production technological process $[3,4]$. According to the experimental tests $[5,6]$ carried out in ACMP of various countries, it was proved that the grading and bitumen of the produced $\mathrm{ACM}$, and, therefore, physical-mechanical indices deviate from project and standard values considerably. The degree of deviations is frequently influenced by the fluctuations of ACM production technological parameters during the working shift. Rokas S. [6] came to a conclusion that during the working shift when the ACM production process is stopped for lack of transport, the change of the mixture composition or the removal of the surplus of hot fractions (HFr), optimal technological parameters misalign, due to which deviations of production quality indices decrease. These theoretical assumptions were not thoroughly assessed due to complicated experimental tests, which shall be carried out in ACMP.
The latest reasarch carried out by Bunkin I. F. (2003) [7] showed that ACM production process shall be improved in modern ACMP as well.

Accumulating bins are used in modern ACMP; therefore, in most cases the production process shall not be stopped for lack of transport. ACM composition has to be changed during the working shift when its various types are supplied to several users (clients). Due to the change of ACM type (composition), not only final but initial dosing of materials shall be corrected as well. Failure to maintain the balance of their mass in hot mineral material bin sections of ACMP results in a surplus of some fractions and lack of the others. If masses of cold and hot materials are not balanced, a surplus has to be removed. In our opinion, when the mass of materials fluctuates in bin sections; their segregation increases as well as serious dosing errors are made when a surplus is not removed in time. The degree of hot fractions segregation was investigated in our research [8-12]; however, the influence of their mass fluctuations in bin sections on the homogeneity of the screened flows has not been analyzed properly.

Investigations [13] showed that hot fractions are weighed with various dosing errors, which depend on the efficiency of the ACMP handling system, set tolerances, dosing succession and other technological factors.

The aim of this research is to analyze the degree of segregation of hot mineral materials separate fractions sieved in ACMP screening equipment and the influence 
of the kinetics of their running from bin sections on the homogeneity of doses falling to the measuring hopper.

\section{Aims and kinetics of hot screening}

When screening the dried and heated mixture of initial mineral materials through technological screens of ACMP, it is believed that the grading of the obtained HFr will be more homogeneous than of cold mineral materials of the corresponding coarseness. It is considered that this supplementary technological operation reduces the variation of initial mineral materials grading forming due to the heterogeneity of their production parameters and characteristics of raw materials as well as segregation while loading, transporting, pouring or moving. In most cases this assumption does not prove correct due to both positive and negative factors of the screening process, especially due to segregation which reduces the homogeneity of HFr grading considerably.

When dried and heated mixture of initial mineral materials is screened continuously, the number and particle size of obtained HFr depend on the number of screens of cylindrical or vibratory screening equipment, their layout (scheme), mesh size and shape. Flows of HFr running into bin sections have different kinetics; therefore their segregation varies. The first $\mathrm{HFr}$ containing the smallest fractions $(0-5,0-4$ or $0-2 \mathrm{~mm})$ running through approximately $6 \mathrm{~mm}, 5 \mathrm{~mm}$ or $3 \mathrm{~mm}$ round or square mesh technological screens of ACMP are formed while they are loosely running (not mixing) on various spots of the screen. First the finest particles, then medium size particles, and finally the largest particles close to the size of the mesh run through the screen. Due to regular screening kinetics such running of the first finest fraction (Fr1) particles through various spots of the technological screen results in a high degree of their segregation and, therefore, uneven distribution in the hot bin section as well. Particles of other fractions, such as the second ( $\mathrm{Fr} 2)$, the third ( $\mathrm{Fr} 3)$, the fourth (Fr4) or the fifth (Fr5) - HFr, running through the upper screen mesh, fall on the bottom screen and at the end of unloading their concentrated flow mixes and runs into the storage bin section. The kinetics of forming $\mathrm{HFr}$ containing larger particles reduces the segregation of the material and increases their homogeneity compared to mineral materials of the first HFr. It was proved theoretically and practically [12] that due to the screening segregation, the obtained first finest $\mathrm{HFr}(\mathrm{Fr} 1)$ are less homogeneous than other larger $\mathrm{HFr}(\mathrm{Fr} 2, \mathrm{Fr} 3, \mathrm{Fr} 4, \mathrm{Fr} 5)$, when gravitational (natural) segregation is the most important cause of their hetereogeneity.

HFr sieved through technological screens of ACMP segregate in bin sections, due to which their grading varies considerably in various places (space, mass). When screening and dosing the quantity of mineral materials in hot bin sections and the degree of filling them during the working shift fluctuates from full (sometimes even overfilled) to almost empty sections. When dosing HFr through a bin section enclosure, first the central part of overfilled material is screened, and when it empties, segregated particles of different sizes fall from its walls. Doses of mineral materials of various grading are obtained in this way. The question 'What is the impact of the fluctuations of the screened HFr (mass, volume) in bin sections on their segregation and the stability of grading?' is posed.

\section{Methodology of experimental investigations}

\subsection{Methodology of a sample selection}

To check the proposed hypothesis that the more (more frequently and at a wider range) $\mathrm{HFr}$ quantity fluctuates in bin sections, the more it segregates and dosed portions of heterogeneous grading run through bin enclosures, we carried out experimental investigation.

We took separate samples of HFr sieved through technological screens of two ACMP (No 1 and No 2) applying 3 methodologies dividing them into three corresponding series: A series, B series, C series.

- A series. In the first stage at the end of the working day when mineral materials were screened through the technological screens of the screening equipment, we took 25 and 10 separate samples from the top of the screened material fractions of $0-5 \mathrm{~mm}$ and $5-15 \mathrm{~mm}$ respectively. A laboratory assistant took samples from the bin dividing the surface into 25 or 10 even areas and taking 4-5 kg of the material from the central part of each area (Fig 1).

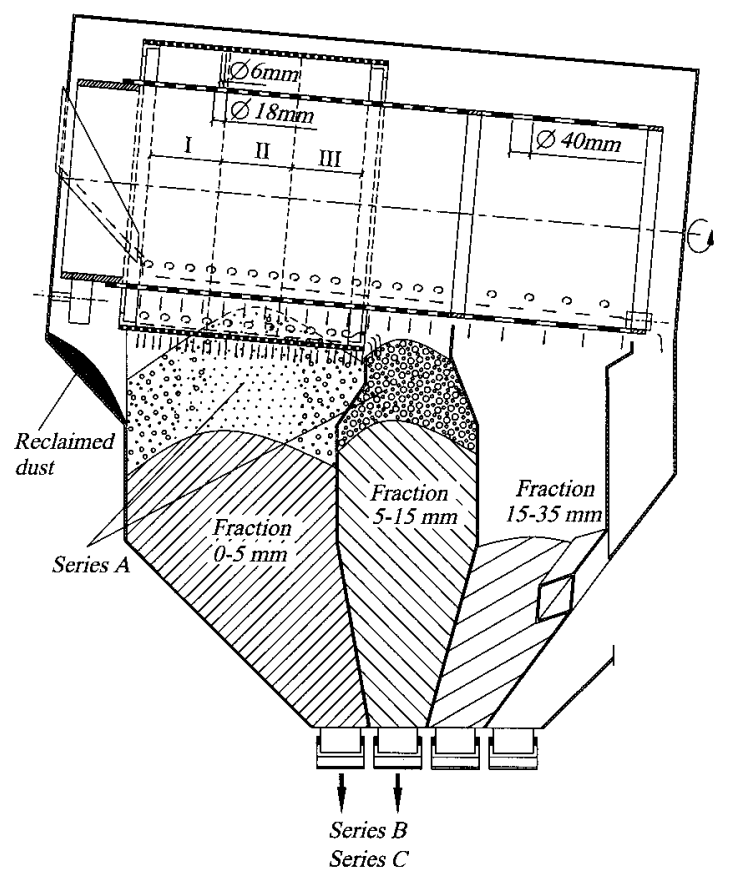

Fig 1. The scheme of ACMP screening equipment construction and separate sample selection areas of screened hot mineral materials 
When investigating separate samples taken from the surface of HFr $0-5 \mathrm{~mm}$ and $5-15 \mathrm{~mm}$, the distribution of the grading of materials screened through the technological screens of ACMP in bin section plan; i.e. the type and degree of their segregation was identified. The analysis of the kinetics of HFr screening process enabled to understand the regularity of their segregation on and under the screen as well as running into the bin section, to develop effective antisegregation equipment and the optimal technological mode of filling the section with the material.

- B series. Having taken fractions of 0-5 mm and $5-15 \mathrm{~mm}$ from the surface of hot mineral materials from the filled sections of ACMP, their distribution in the flow running from the bin section was investigated. When the enclosure of each section of ACMP No 1 and 2 was opened, the flow of materials running from it was completely cut by a sampling device. Then 27 and 22 separate samples of fraction of $0-5 \mathrm{~mm}$ as well as 17 and 8 separate samples of fraction of 5-15 mm were taken.

Under real production conditions ACMP rarely works when HFr quantity in bin sections fluctuates from maximum to minimum. When mineral materials are finally discretely dosed, they are continuously screened, due to which HFr quantity in bin sections (the degree of filling them with the material) varies insignificantly if the actual productivity of initial cold materials' continuous measuring hopper-suppliers is identified properly.

- C series. When investigating how HFr 0-5 mm and $5-15 \mathrm{~mm}$ segregate and how their grading fluctuates due to this, working with full, continuously filled sections, they are filled with these fractions at the beginning of the next working day. Continuing the process of HFr dosing, we discretely dosed and took 1-2 separate samples from each portion (dose) of the running flows. Samples were taken from such quanity of each HFr, which approximately goes to the full section. We took 25 and 24 separate samples of fraction of $0-5 \mathrm{~mm}$ as well as 11 and 10 separate samples of fraction of 5-15 $\mathrm{mm}$ from each ACMP.

\subsection{Investigation of sample characteristics}

In total, 214 separate samples were taken for this experiment: $148 \mathrm{HFr}$ of 0-5 mm and $66 \mathrm{HFr}$ of 5-15 mm. Each of them was screened through a full set of control screens, and the mass of the complete screenings in per cent was calculated. To express the coarseness of all particles of each sample by one number, coarseness modulus $M_{s t}$ for fraction of $0-5 \mathrm{~mm}$ was calculated according to formula (1) and arbitrary coarseness modulus $M_{s t ~}$ s for fraction of 5-15 mm was calculated according to formula (2).

The grading of mineral materials may be expressed by one number called a coarseness modulus $M_{s t}$, which was standardized and regulated for natural sand and sift- ings. The coarseness modulus of mineral materials is calculated according to the following formula:

$$
M_{s t}=\frac{p l_{2,5}+p l_{1,25}+p l_{0,63}+p l_{0,315}+p l_{0,14}}{100}
$$

here $p l_{2,5}-$ cumulative residue on the control screen with round mesh of $2,5 \mathrm{~mm}$ diameter, mass \%; $p l_{1,25}, \quad p l_{0,63}, \quad p l_{0,315}, \quad p l_{0,14}$ - cumulative residue on control screens with square mesh of $1,25 \mathrm{~mm}, 0,63 \mathrm{~mm}$, $0,315 \mathrm{~mm}$ and $0,14 \mathrm{~mm}$ sides, mass $\%$.

Larger values of coarseness modulus $M_{s t}$ correspond to the grading of the majority of larger particles and siftings. Therefore, this index expressing the grading of sand group mineral material separate sample or average sample expressed by one number may be used to evaluate the coarseness of the finest $\mathrm{HFr}(0-5 \mathrm{~mm}, 0-$ $2 \mathrm{~mm}, 0-4 \mathrm{~mm}$ ) screened through the technological screens of ACMP. The standard calculation formula (1) does not take into account the mass in per cent of all residual particles on $0,071 \mathrm{~mm}$ control screen and the bottom (on bottom $p l_{d}=100 \%$ ). Failure to use cumulative residues of all standard sizes of particles when calculating $M_{s t}$ reduces the suitability of this value to express the grading by one number of mineral materials containing quite a lot of finest particles. However, $M_{s t}$ is a completely suitable index to carry out comparative analysis of separate sample grading and it was successfully used in our investigations.

To express the grading of larger than the finest ( $0-5$ $\mathrm{mm}, 0-2 \mathrm{~mm}, 0-4 \mathrm{~mm}$ HFr) particles of mineral materials by one number, arbitrary coarseness modulus $M_{s t} s$ proposed by us [12] may be used, which is calculated for HFr 5-15 $\mathrm{mm}$ by the following formula:

$$
M_{s t ~ s}=\frac{p l_{15}+p l_{10}+p l_{5}+p l_{2,5}+p l_{1,25}+p l_{0,63}+p l_{0,315}+p l_{0,14}}{100}
$$

here $p l_{15}, p l_{10}, p l_{5}, p l_{2,5}$ - cumulative residue on control screens with round mesh of $15 \mathrm{~mm}, 10 \mathrm{~mm}, 5 \mathrm{~mm}$, $2,5 \mathrm{~mm}$ diameter, mass $\% ; p l_{1,25}, p l_{0,63}, \quad p l_{0,315}$, $p l_{0,14}$ - cumulative residue on control screens with square mesh of $1,25 \mathrm{~mm}, 0,63 \mathrm{~mm}, 0,315 \mathrm{~mm}, 0,14 \mathrm{~mm}$, mass $\%$.

Even though coarseness modulus $M_{s t}$ and arbitrary coarseness modulus $M_{s t s}$ of mineral mineral materials (mixture) have certain disadvantages, they are quite suitable for comparing the grading of separate samples, expressed by one number. They are always bigger than a sample containing a greater quantity of larger narrow fraction particles. Their statistical indices for A, B, C series samples (arithmetical mean $\bar{M}_{s t}$ and $\bar{M}_{s t} s$, standard deviation (SD) $S$, variation coefficient $V$ and the range of spread $R$ ) were calculated according to standard formulae. 


\section{Empirical data analysis}

Grading $M_{s t}$ and $M_{s t} s$ and statistical characteristics such as aritmetical average $\bar{X}, \bar{M}_{s t}, \bar{M}_{s t}, \mathrm{SD}$ $S$, variation coefficient $V$ and range $R$ calculated for all samples taken from ACMP No 1 and No 2 A, B, and $\mathrm{C}$ series enabled to identify the homogeneity of HFr.

Values of each series separate samples grading stability expressed by complete screenings through control screens SD $S_{p i}$, show that they vary considerably (Fig 2). The highest values $S_{p i}$ were obtained from separate samples of series A, medium samples from series B and the lowest from series $\mathrm{C}$. Although the mass of complete screenings through a majority of control screens shows this tendency, for some screens it is not unambiguous and, therefore, does not enable to compare the homogeneity of materials. It is due to different arithmetical mean $\bar{X}_{p i}$ of separate series sample complete screenings, partially influencing values $S_{p i}$ of SD. We identified $[9,12]$ that the mass SD of complete screenings of HFr 0-5 mm and 5-15 $\mathrm{mm}$ through control screens closely correlate with their arithmetical mean. The highest values $S_{p i}$ were obtained for the particles of such diameter, the mass of which in mineral materials makes up 50 $\%$ of its total mass. SD of the quantity of finer and larger particles, the mass of which is 'moving' from $50 \%$ of screenings through control screens, of the mineral material reduces approximating to zero.

Standard deviation $S_{p i}$ of complete screenings of each series separate samples through control screens is not only the function of HFr segregation degree $(S D)$ sample selection place $(S S P)$, running mode of the material from a bin section $(R M)$, but also the function of particle average quantity $\bar{X}_{p i}$ in them:

$$
S_{p i}=f\left(S D, S S P, R M, \bar{X}_{p i}\right) .
$$

Calculated $M_{s t}$ (fraction 0-5 mm) and $M_{s t s}$ (fraction $5-15 \mathrm{~mm}$ ) of each separate sample taken from the top of the bin sections of ACMP filled with materials (series A), which are presented in Fig 3 a, Fig 4 a and schemes, show their great variation. When cylindrical screening equipment rotates in the direction presented in the scheme, the particles of the largest fraction $0-5 \mathrm{~mm}$ close to $5 \mathrm{~mm}$ freely fall on points No 19, 20, 23, 24, 25 (Fig 3 a). Particles of various diameters running through a mesh on various spots of technological screens form clearly expressed conglomerations of various size particles.

When HFr 0-5 mm material runs from the full bin section, separate parts of its mass fall through the open enclosure according to a certain sequence. Separate zones of coarseness partially mix and increase the homogeneity of the material. 22 separate samples taken from the running flow of HFr 0-5 mm (B series Fig 3 a) have almost the same average $\bar{M}_{s t}=3,34$ as well as samples

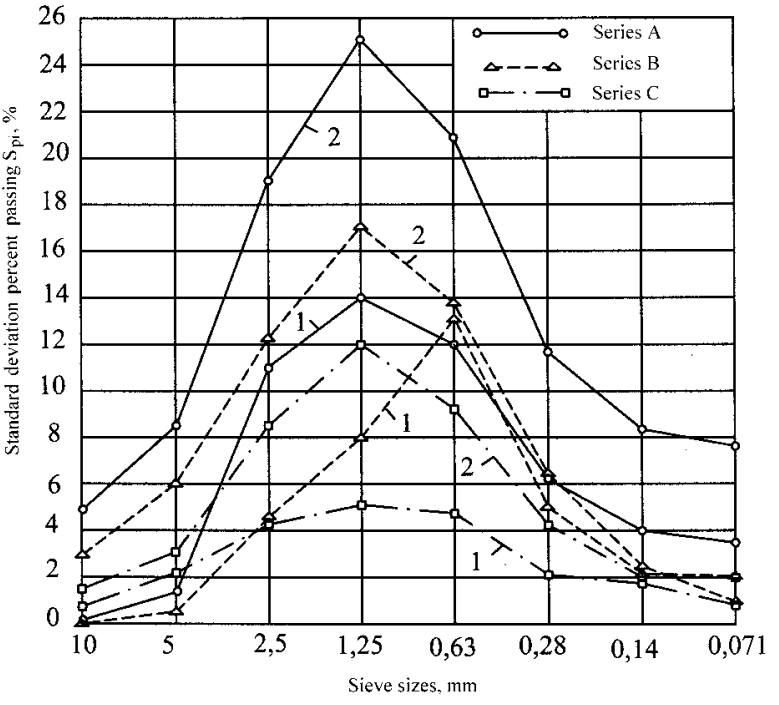

a)

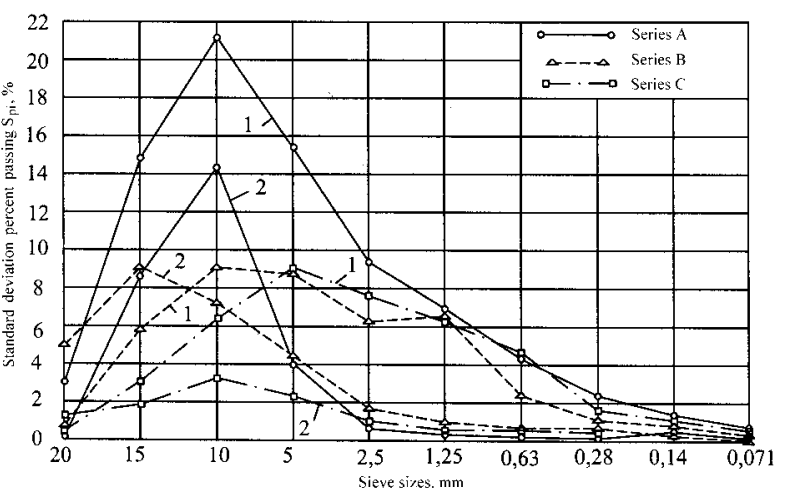

b)

Fig 2. Dependence of finally dosed hot mineral materials grading (complete screenings through control screens) stability values on the place of separate sample selection and the running mode from D-508-2A model ACMP (No 1 and 2) bin section: $\mathrm{a}$ - fraction $0-5 \mathrm{~mm}$; $\mathrm{b}$ - fraction $5-15 \mathrm{~mm}$

taken from the top of the material $\left(\bar{M}_{s t}=3,02\right)$; however the obtained SD of flow coarseness modulus $S=0,55$ is lower than of samples taken from the top, which was $S=0,81$ (Fig $3 \mathrm{a}, \mathrm{b}$ ). When taking separate samples of HFr 0-5 mm from the flow of material running from a full to an empty section, even though its segregation decreases, it is still very high and not acceptable (the difference between the highest $M_{s t \text { max }}=4,42$ and the lowest $M_{s t \text { min }}=2,26$ is close to 2 , and it ranges at $R=2,16$ ).

When HFr 0-5 mm quantity in bin sections does not fluctuate, 24 separate samples taken from the running falling flow show that the influence of segregation on the homogeneity of hot mineral material may be reduced using this method (Fig $3 \mathrm{c}$ ). The mean of coarseness modulus $\bar{M}_{s t}=3,29$ did not change; however its SD $S$ decreased from 0,55 (B series) to 0,38 (series $\mathrm{C}$ of this 


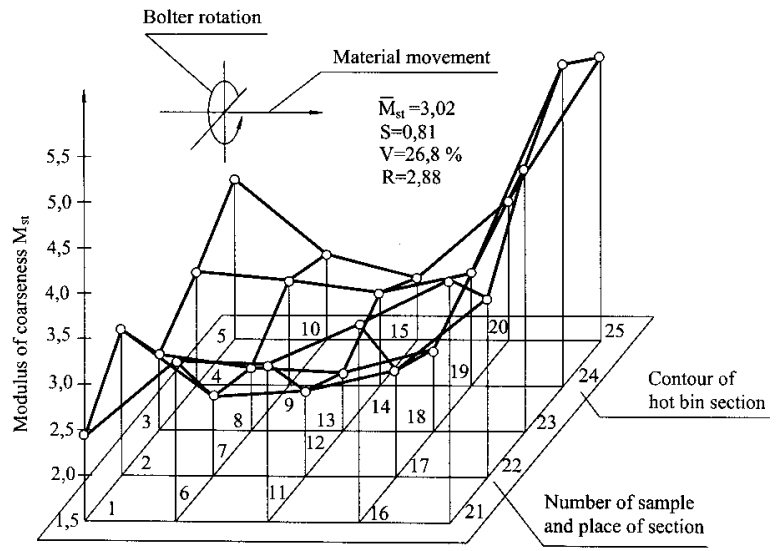

a)

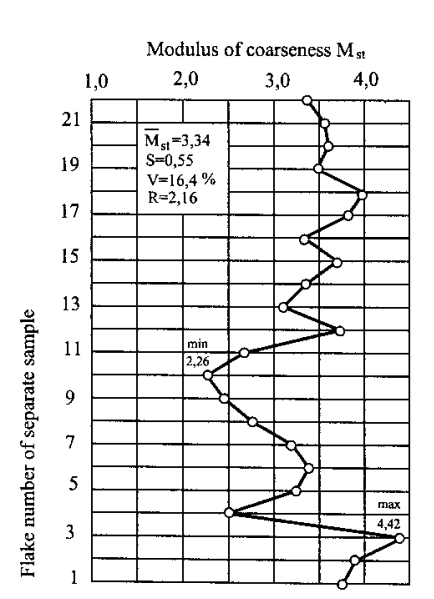

b)

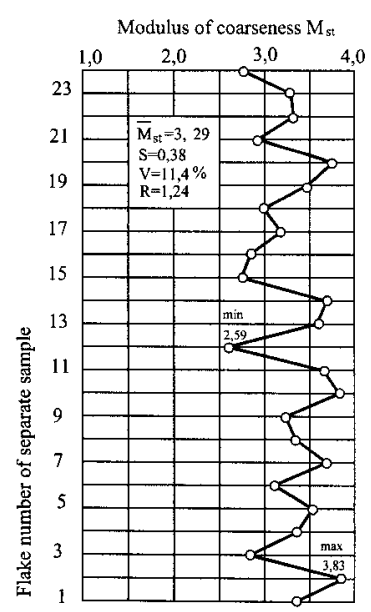

c)
Fig 3. Distribution of coarseness modulus $M_{s t}$ of HFr 0-5 mm sieved through technological screens of ACMP No 2, when separate samples are taken from the following: $\mathrm{a}-$ the top of the material when the bin section is filled (A series); b - flow running through an enclosure from the full section when screening is stopped (B series); $\mathrm{c}$ - flow running through an enclosure from the full section by sieving and dosing at a constant mass balance ( $\mathrm{C}$ series)

experiment). Therefore, when producing ACM during the working shift, it is expedient to store a stable quantity of $\operatorname{HFr}(R=3,83-2,59=1,24)$ in bin sections.

Average values $\bar{M}_{s t}$ of HFr $5-15 \mathrm{~mm}$ separate

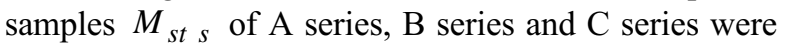
almost the same (respectively equal to $6.73 ; 6.62$ and 6,45 ) (Fig 4). When changing the sample selection method, SD $S$ of the arbitrary coarseness modulus was decreasing respectively resulting in 0,28 (A series), 0,29 (B series) and 0,07 (C series). These data enable to make a very important conclusion that the influence of HFr 5$15 \mathrm{~mm}$ segregation in bin sections on the homogeneity of the parts of the flow running to separate doses (due to the homogeneity of the produced ACM) may be reduced

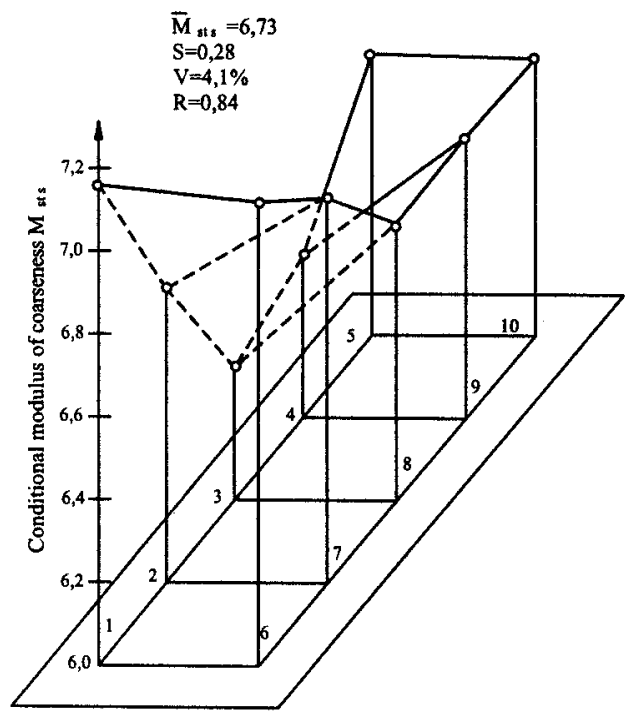

a)

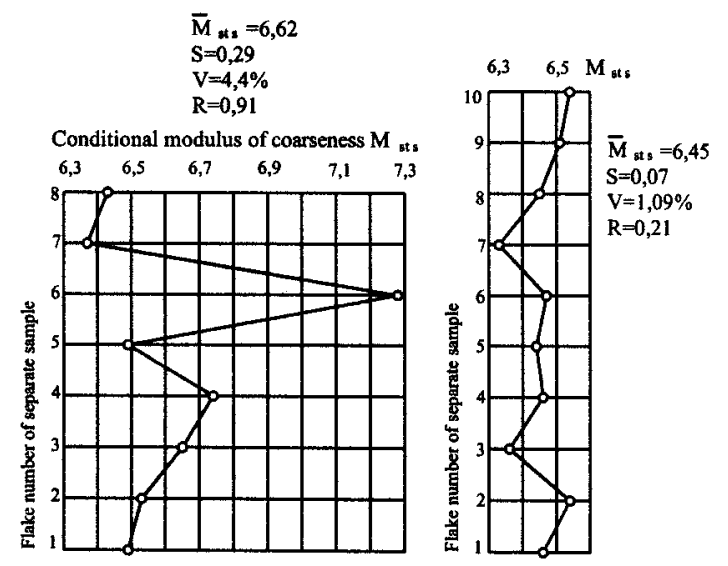

b)

Fig 4. Distribution of HFr 5-15 $M_{s t} s$ sieved through technological screens of cylindrical screening equipment ACMP No 2 (D-508-2A) when separate samples are taken from the following: a material top after the bin section is filled (A series); $\mathrm{b}$ - flow running from the full section through the enclosure when screening is stopped (B series); $\mathrm{c}$ - flow running through the enclosure from the full section by sieving or dosing it at a constant mass balance (C series)

by maintaining maximally the same quantity of the material in bin sections during the working shift.

The comparative analysis data of two ACMP (No 1 and No 2) (Fig 5) show the same influence of the sample selection place and the unloading mode of bin sections on the homogeneity of HFr (segregation) values for numerical values. The stability of grading of HFr 0-5 mm and 5-15 mm sieved through technological screens of both ACMP flows running from bin sections depends on the fluctuation of the material quantity in these sections. The influence of the running mode on the homogeneity of flow is bigger for $0-5 \mathrm{~mm}$ fraction hot material. 

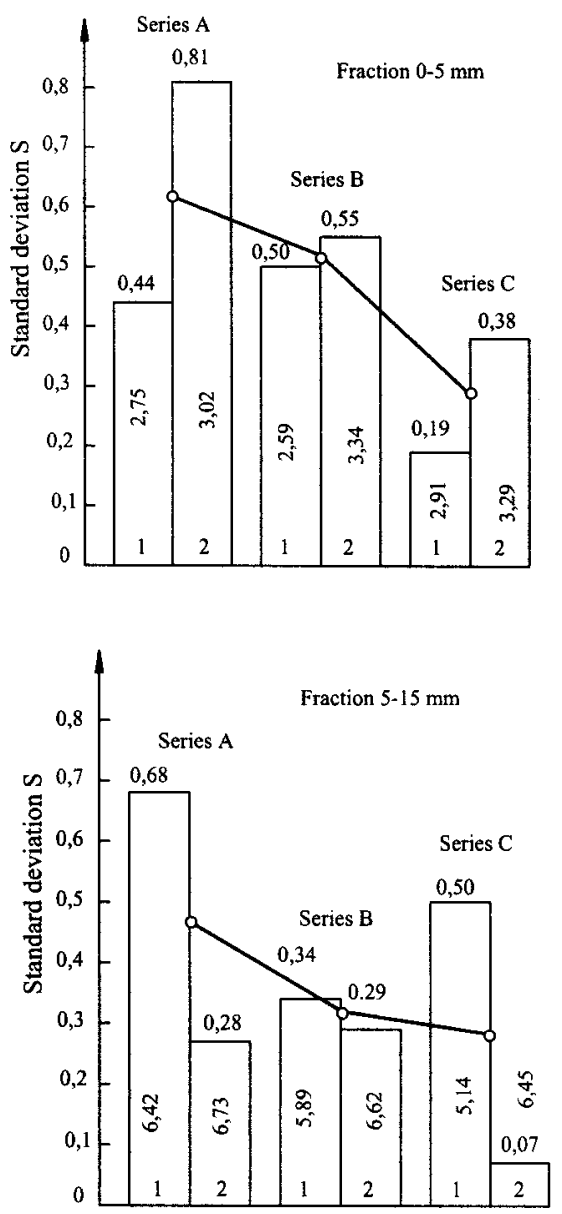

Fig 5. Dependence of the degree of segregation of hot mineral materials sieved through technological screens of D-508-2A model ACMP (No 1 and 2) screening equipment on the sample selection place and the unloading mode of bin sections

\section{Conclusions}

1. Deviations of the produced ACM component quantity from project values are reduced by stabilizing the parameters of the technological process operations. The technological process of production has to be cancelled (stopped) during the working shift due to the following factors:

- lack of transport to carry the produced ACM to the place of construction when the accumulating bin is not used;

- change of ACM type and mark when various clients request it;

- removal of one or several fractions from the material in overfilled sections of the hot bin when there is no chute for surplus flow or when it works ineffectively;

- waiting until a minimum quantity of materials of all fractions is to screened to hot bin sections.

Hot fractions (HFr) sieved through technological screens of the ACMP bin sections segregate dividing into larger and finer particles. Their segregation reduces the homogeneity of hot mineral material flows (doses) running from bin sections. When heterogeneous mineral materials are finally dosed, ACM of unstable characteristics are produced.

2. The type and degree of segregation of $\mathrm{HFr}$ sieved through technological screens in bin sections of two ACMP, were investigated by taking separate samples of materials according to three different methodologies from: the top of sections filled with material, divided into equal squares (10...25 samples) (series A); running flow ( $8 \ldots 27$ samples) by cutting it at equal distances by a sampling device when an emptying full section is not filled with the material (series B) and falling flow (10...25 samples), when the same amount of the material is poured to the full section (series C). The lowest obtained AQD of HFr samples grading, coarseness modulus and arbitrary coarseness modulus of series $\mathrm{C}$ show that the homogeneity of materials running from bin sections may be increased not only by using antisegregation equipment constructed by us, but by a properly organized technological mode, i.e. the same mass of screened materials in hot bin sections is maintained.

\section{References}

1. Guideline of construction R35-10. Asphalt concrete and grit cover automobile roads (Statybos rekomendacijos R3501. Automobilių kelių asfaltbetonio ir žvyro dangos). Vilnius: LAKD, 2001. 117 p. (in Lithuanian).

2. Regulation. Motor roads STR 2.06.03:2001 (Statybos techniniai reglamentai STR 2.06.03:2001. Techniniu reikalavimu reglamentas. Automobilių keliai. Pirmasis leidimas). Vilnius, 2002. 50 p. (in Lithuanian).

3. Roberts F. L., Kandhal P. S., Brown E. R., Lee D. Y., Kennedy T. W. Hot mix asphalt materials, mixture design and construction, Lanham, Maryland: NAPA Research and Education Foundation. 1991. 490 p.

4. Bituminous mixtures in road construction. Edited by Robert N. Hunter. London: Thomas Telford, 1997. 441 p.

5. Borisov V. A. Technological accuracy asphalt concrete plants and methods of its increase (Технологическая точность асфальтобетонных заводов). Saratov: Izdatelstvo Saratovskogo universiteta, 1975. 159 p. (in Russian).

6. Rokas S. Statistical control of quality in road construction (Статистический контроль качества в дорожном строительстве). Moscow: Transport, 1987. 152 p. (in Russian).

7. Bunkin I. F. Automation of asphalt concrete production management. Summary of the research report presented for habilitation (Автореферат диссертации на соискание ученой степени доктора технических наук). Moscow, 2003. 33 p. (in Russian).

8. Sivilevičius H. Influence of homogeneity of mineral mate- 
rials' grading and dosing erros on the stability of asphalt concrete mixture composition. Journal of Civil Engineering and Management, 2003, Vol IX, No 1, p. 25-35.

9. Sivilevičius $\mathrm{H}$. Theoretical principles and experimental data to identifity stability of asphalt concrete components in finally dosed mineral materials. Transport, 2002, Vol XVII, No 1, p. 19-29 (in Lithuanian).

10. Vitkūnas R., Sivilevičius H. The efect of hot fraction segregation on the homogenousity of bituminous concrete mixture production. In: The set of scientific reports for the republican conference "Transport - 2000", held in Vilnius, April 5-6, 2000. Vilnius: Technika, 2000, p. 237-242 (in Lithuanian).

11. Vitkūnas R. Methods and equipment for reduction of segregation of mineral substances screened in bituminous concrete mixer. Summary of doctoral dissertation. Vilnius: Technika, 2000. 48 p.

12. Sivilevičius H. The quality improvement system of asphalt concrete mixture production technological process. Summary of research report presented for habilitation. Vilnius: Technika, 2003. $37 \mathrm{p}$.

13. Sivilevičius H., Karalevičius J., Gailius A. Statistical evaluation of technological indicators of the new compiuterised asphalt concrete mixing plant materials discrete dosing units. Journal of Civil Engineering and Management, Vol IX, Suppl 2, Vilnius: Technika, 2003, p. 131-140 (in Lithuanian). 